\title{
The risks and rewards of covariate adjustment in randomized trials: an assessment of 12 outcomes from 8 studies
}

\author{
Brennan C Kahan ${ }^{1 *}$, Vipul Jairath², Caroline J Doré ${ }^{3}$ and Tim P Morris ${ }^{4}$
}

\begin{abstract}
Background: Adjustment for prognostic covariates can lead to increased power in the analysis of randomized trials. However, adjusted analyses are not often performed in practice.

Methods: We used simulation to examine the impact of covariate adjustment on 12 outcomes from 8 studies across a range of therapeutic areas. We assessed (1) how large an increase in power can be expected in practice; and (2) the impact of adjustment for covariates that are not prognostic.

Results: Adjustment for known prognostic covariates led to large increases in power for most outcomes. When power was set to $80 \%$ based on an unadjusted analysis, covariate adjustment led to a median increase in power to $92.6 \%$ across the 12 outcomes (range 80.6 to 99.4\%). Power was increased to over $85 \%$ for 8 of 12 outcomes, and to over $95 \%$ for 5 of 12 outcomes. Conversely, the largest decrease in power from adjustment for covariates that were not prognostic was from $80 \%$ to $78.5 \%$.

Conclusions: Adjustment for known prognostic covariates can lead to substantial increases in power, and should be routinely incorporated into the analysis of randomized trials. The potential benefits of adjusting for a small number of possibly prognostic covariates in trials with moderate or large sample sizes far outweigh the risks of doing so, and so should also be considered.
\end{abstract}

Keywords: Adjusted analysis, clinical trial, covariate adjustment, power, randomized controlled trial, regression

\section{Background}

Adjustment for baseline covariates in the analysis of randomized controlled trials (RCTs) can lead to a substantial increase in power when the covariates are highly prognostic [1-10]. Hernandez et al. found that increases in power of over $20 \%$ are possible in certain circumstances [3], and this has been demonstrated in simulation studies based on real datasets $[1,2,6]$ and confirmed through reanalysis of an RCT [8]. Other benefits of adjustment include protection against chance imbalances in important baseline covariates [7], and maintaining correct type I error rates when the covariates have been used in the randomization process [11-14].

\footnotetext{
* Correspondence: b.kahan@qmul.ac.uk

${ }^{1}$ Pragmatic Clinical Trials Unit, Queen Mary University of London, London E1 $2 \mathrm{AB}, \mathrm{UK}$

Full list of author information is available at the end of the article
}

Despite these benefits, unadjusted analyses dominate in practice; reviews have found that between 24 and 34\% of trials use covariate adjustment for their main analysis [15-19]. It is unclear why so few RCTs perform adjusted analyses. Researchers may be unsure or sceptical as to how much of an increase in power is likely to occur in practice. Few articles have examined this issue using real data, and most have been limited to datasets in traumatic brain injury $[2,5,8]$ or Alzheimer's disease [20]. Further research to assess the potential increase in power through adjustment for known prognostic factors, and the decrease in power through adjustment for nonprognostic factors, would allow researchers to make more informed decisions as to whether covariate adjustment is likely to be worthwhile in their own trial.

In this paper we give an overview of the benefits and risks of covariate adjustment in RCTs, using examples from a previously published trial. We then examine 12 
outcomes from 8 different studies in a variety of disease areas to determine (1) the likely increase in power through adjustment for known prognostic covariates; and (2) the likely decrease in power through inadvertently adjusting for nonprognostic covariates.

\section{Methods}

Benefits of covariate adjustment

We describe some of the benefits of covariate adjustment next, and illustrate these concepts using data from the Second Multi-centre Intra-pleural Sepsis Trial (MIST2) [21]. MIST2 was a four-arm trial that compared tissue plasminogen activator (tPA), DNase and tPA + DNase against placebo in patients with a pleural effusion. We focus here on the treatment comparison between the $\mathrm{tPA}+\mathrm{DNase}$ and placebo groups, for simplicity. The primary outcome measure was the change from baseline to day 7 in the size of the patient's pleural effusion (a continuous outcome). A major secondary outcome measure was the need for surgery at 90 days (a binary outcome). Patients were randomized using minimization [22-25]; stratification factors were: the size of the pleural effusion at baseline; whether the infection was hospital-acquired, and the presence of purulent pleural fluid.

\section{Increase in power (continuous outcomes)}

One of the main advantages of covariate adjustment is that it can lead to increased power. For continuous outcomes, this occurs because the covariates help to explain some of the variation in outcomes between patients, leading to smaller standard errors (SEs) for the treatment effect. The amount by which the SE is reduced depends on the correlation between the covariates and the outcome; the higher the correlation, the larger the increase in power [4].

This is particularly relevant for continuous outcomes that are also measured at baseline (for example, a pain score might be measured at baseline and again at 6 months). These baseline measurements are generally highly correlated with outcome, and so adjustment can lead to substantial gains in power $[7,26]$. This is true regardless of whether the outcome measure is defined as the measurement at 6 months, or as a change from baseline to 6 months; as long as the analysis adjusts for the baseline measurement, both analyses provide identical treatment effect estimates and SEs.

In the MIST2 trial, the correlation between the size of the patient's pleural effusion at baseline and day 7 was 0.44. Accounting for baseline effusion size in the analysis resulted in a large reduction in the SE of the treatment effect (unadjusted SE of 4.3 vs adjusted SE of 2.8; a 35\% reduction), leading to a substantial increase in power.

\section{Increase in power (binary and time-to-event outcomes)}

Adjusting for important prognostic covariates in the analysis of a binary or time-to-event outcome when estimating an odds ratio or hazard ratio will also lead to an increase in power. However, unlike continuous outcomes, where adjusting for important covariates leads to a reduction in the SE, adjusting for important covariates with a binary or time-to-event outcome will generally lead to larger SEs; however, this increase in the SE is offset by an increase in the estimated treatment effect; that is, estimated odds or hazard ratios will be further from 1 (where an odds or hazard ratio of 1 indicates no treatment effect), assuming that there is a true treatment effect. Therefore, adjustment for covariates with a binary or time-to-event outcome will generally lead to a loss in precision (wider confidence intervals) but increased power $[9,10]$.

This difference occurs because the methods are estimating different treatment effects. Adjusted analyses lead to subject-specific (or conditional) estimates, which compare an 'intervention' patient with a 'control' patient with the same covariates. Unadjusted analyses lead to marginal (or population-averaged) estimates, which compare an intervention' patient with a 'control' patient who has been randomly selected from the trial, regardless of their covariate values. For continuous outcomes, subject-specific and marginal analyses have the same expected treatment effect, but this is not generally the case for binary and timeto-event outcomes [9].

In the MIST2 trial, adjustment for the size of the pleural effusion at baseline in the analysis of surgery at 90 days led to increases in both the size of the treatment effect and its SE: an unadjusted $\log$ (odds ratio) of -1.14 (SE, 0.84) vs an adjusted value of -1.46 (SE, 0.87). However, because the increase in the treatment effect through adjustment was much higher than the increase in the $\mathrm{SE}$, this led to a substantial increase in the $Z$ statistic (unadjusted -1.36 vs adjusted -1.67; a $23 \%$ increase), leading to increased power.

\section{Protection against chance imbalance in important baseline covariates}

Randomization ensures that, on average, both known and unknown covariates are well balanced between treatment groups [23]. However, randomization does not guarantee balance; in any individual trial, there may be large imbalances in important prognostic covariates between treatment groups merely by chance. Any such imbalance can give an unfair advantage to one treatment group over another if not accounted for in the analysis. Therefore, prespecifying that important baseline covariates are included in the analysis will help to ensure that any chance imbalances between treatment groups in these covariates will not affect treatment effect estimates [27]. 
In the MIST2 trial, there was an imbalance between treatment arms in the size of the pleural effusion at baseline (mean placebo 39 (standard deviation (SD), 22) vs mean tPA + DNase 47 (SD 24)). Because the size of the effusion at baseline was highly correlated with the size at day $7(0.44)$, this imbalance gave an unfair advantage to the tPA + DNase group. The unadjusted treatment effect was -12.3 , but was reduced to -7.6 after adjustment (a $38 \%$ reduction).

\section{Appropriate confidence intervals and $P$ values after stratified randomization}

Many trials use stratified randomization to balance key prognostic covariates between treatment arms. A recent review found $63 \%$ of trials used at least one stratification factor; however, only $26 \%$ of these appropriately accounted for these variables in their primary analysis [12]. If the stratification factors are associated with outcome, then stratified randomization has the effect of forcing the outcomes between treatment groups to be more similar than they otherwise would be. This leads to correlation between the treatment groups, which violates the standard statistical assumption of independence. If this correlation is ignored (by not adjusting for the stratification factors in the analysis) then the SE for treatment effect will be biased upwards, leading to confidence intervals that are too wide, $P$ values that are too large, incorrect type I error rates and a reduction in power. Conversely, accounting for the stratification factors in the analysis leads to correct SEs and no loss in power [11-14,28]. Therefore, it is essential that stratification factors be accounted for in the trial analysis.

The MIST2 trial used three stratification factors in the randomization process. Previous research has shown that not accounting for these stratification factors in the analysis led to SEs that were biased upwards by 14 to $15 \%$, which in turn led to type I error rates of around $2.6 \%$ (rather than the nominal 5\%). This resulted in major reductions in power (adjusted $80 \%$ vs unadjusted 59\%) [11].

\section{Risks of covariate adjustment}

\section{Loss in power due to adjustment for nonprognostic} covariates

Although adjustment for prognostic covariates can lead to increased power, adjustment for nonprognostic covariates can lead to increased SEs, and thus a decrease in power. This occurs because each continuous or binary baseline covariate uses a 'degree of freedom', which effectively reduces the sample size, meaning that there is less information with which to estimate the treatment effect (in cases where the covariate actually is prognostic, the benefits of the prognostic ability outweigh any loss of information, and power will be increased despite the loss of a degree of freedom). This is particularly an issue with small sample sizes (as reducing the effective sample size from 50 to 40 patients through adjustment for 10 nonprognostic covariates will have a much larger impact than reducing it from 500 to 490 patients). Therefore, caution is required in the number of covariates that are included in the analysis if the sample size is small.

\section{Inflation of the type I error rate due to overstratification}

Covariate adjustment can lead to inflated type I error rates (that is, increased probability of a false positive) when there is a small sample size and a binary or timeto-event outcome $[11,29]$. This is because covariate adjustment can lead to overstratification in these situations, meaning that there are too many covariates in relation to the number of observed events. It is therefore important to keep the overall sample size and expected event rate in mind when deciding how many covariates to include in the analysis.

\section{Missing data on covariates}

If some patients are missing data on certain covariates that were to be included in the analysis, it may be unclear how to proceed. Two unsatisfactory options are to perform a complete case analysis (where patients with missing values for the covariates are excluded from the analysis) and to exclude covariates with missing data from the analysis. A complete case analysis is unsatisfactory as it will reduce the sample size, and therefore reduce power (the opposite of our intention). Excluding covariates with missing data from the analysis is similarly unsatisfactory, as it deviates from the prespecified analysis plan, and might result in key prognostic covariates being excluded, negating some of the benefits of adjustment.

A preferable and simple alternative is to use mean imputation [30], where the missing values are replaced with the mean of the observed data. This has been shown to give unbiased estimates of treatment effect and preserve the type I error rate in RCTs (unlike in observational studies, where it can lead to bias). This allows all patients to be included in the analysis, and should therefore increase power compared with a complete case analysis, or one that excludes the covariate. Other simple and appropriate methods of dealing with missing baseline data are also available [30].

\section{Bias due to data-driven methods of choosing covariates}

Methods are available to identify which covariates to include in the analysis, such as stepwise selection, where variables with large $P$ values are removed, or by adjusting for covariates with a large observed difference between treatment arms at baseline. Reviews have found that between $16 \%$ and $31 \%$ of trials use these methods 
$[15,17,18]$. However, these methods use the trial data to decide which covariates to include, and have been shown to lead to incorrect type I error rates in many situations [31]. Prespecifying which variables will be included in the analysis in the protocol or analysis plan will avoid bias, and give more credibility to the trial results.

\section{Simulation study}

We performed a simulation study to assess the increase or decrease in power from covariate adjustment across a number of outcomes and studies in a variety of different disease areas.

We performed simulations for 12 different outcomes (four continuous, six binary, two time-to-event) based on 8 different studies. The studies were the AUGIB study [32-35], the Function After Spinal Treatment, Exercise, and Rehabilitation (FASTER) trial [36], the MIST2 trial [21], the MOSAIC trial [37], the primary biliary cirrhosis (PBC) trial [38], the PROGRAMS trial [39], the RE01 trial [40] and the TIME2 [41] trial. Further information on each study is available in Table 1 and in Additional file 1.

Full details of the simulation study can be found in Additional file 1. Briefly, we simulated 5,000 datasets for each outcome and the simulated data were based on parameter estimates obtained from the study datasets. We used two different treatment effects; one was calculated to give $50 \%$ power (referred to as an 'underpowered' trial) and the other to give $80 \%$ power (an 'adequately powered' trial), based on an unadjusted analysis. We used between one and four known prognostic covariates for each outcome, taken from the study datasets.

For each outcome, we compared power between four different methods of analysis: (1) unadjusted for all baseline covariates; (2) adjusted for known prognostic covariates; (3) adjusted for three 'random-noise' covariates (which were not related to the outcome); and (4) adjusted for both known prognostic and 'noise' covariates. We assessed the impact of included noise covariates to determine how much of a loss in power to expect from adjusting for covariates that were not related to outcome. All analyses were performed using a regression model (linear regression for continuous outcomes, logistic regression for binary outcomes and a Cox model for time-to-event outcomes). Adjusted analyses were performed by including the covariates in the regression model. All covariates were kept in the model, regardless of statistical significance; this was to reflect adherence to a predefined analysis plan.

Table 1 Description of studies

\begin{tabular}{|c|c|c|c|c|c|c|}
\hline Study & Disease area & Study type & Sample size & Outcome measure & Outcome type & Prognostic covariates \\
\hline \multirow[t]{3}{*}{ AUGIB } & \multirow{3}{*}{$\begin{array}{l}\text { Acute upper } \\
\text { gastrointestinal } \\
\text { bleeding }\end{array}$} & \multirow{3}{*}{$\begin{array}{l}\text { Observational } \\
\text { study }\end{array}$} & \multirow[t]{3}{*}{$600^{a}$} & Mortality in hospital & Binary & (1) clinical Rockall score \\
\hline & & & & $\begin{array}{l}\text { Further bleeding in } \\
\text { hospital }\end{array}$ & Binary & (1) clinical Rockall score \\
\hline & & & & $\begin{array}{l}\text { RBC transfusion in } \\
\text { hospital }\end{array}$ & Binary & $\begin{array}{l}\text { (1) presence of shock; ( } 2 \text { ) haemoglobin } \\
\text { concentration at baseline }\end{array}$ \\
\hline FASTER & $\begin{array}{l}\text { Postoperative } \\
\text { rehabilitation }\end{array}$ & $\mathrm{RCT}$ & 316 & $\begin{array}{l}\text { Oswestry disability } \\
\text { index }\end{array}$ & Continuous & $\begin{array}{l}\text { (1) Oswestry disability index at baseline; } \\
\text { (2) type of surgery }\end{array}$ \\
\hline \multirow[t]{2}{*}{ MIST2 } & \multirow[t]{2}{*}{$\begin{array}{l}\text { Malignant pleural } \\
\text { effusion }\end{array}$} & \multirow[t]{2}{*}{$\mathrm{RCT}$} & \multirow[t]{2}{*}{210} & $\begin{array}{l}\text { Size of the patient's } \\
\text { pleural effusion at } \\
7 \text { days }\end{array}$ & Continuous & $\begin{array}{l}\text { (1) size of the pleural effusion at baseline; } \\
\text { (2) hospital-acquired infection; (3) large } \\
\text { tube size; (4) drain present }\end{array}$ \\
\hline & & & & $\begin{array}{l}\text { Need for surgery at } \\
90 \text { days }\end{array}$ & Binary & $\begin{array}{l}\text { (1) size of the pleural effusion at baseline; } \\
\text { (2) large tube size }\end{array}$ \\
\hline MOSAIC & Sleep apnoea & $\mathrm{RCT}$ & 391 & $\begin{array}{l}\text { Epworth Sleepiness } \\
\text { Score }\end{array}$ & Continuous & $\begin{array}{l}\text { (1) Epworth Sleepiness Score at baseline; } \\
\text { (2) sex; (3) MRI received at baseline }\end{array}$ \\
\hline PBC & $\begin{array}{l}\text { Primary biliary } \\
\text { cirrhosis }\end{array}$ & $\mathrm{RCT}$ & 312 & Time to death & Time-to-event & $\begin{array}{l}\text { (1) age; (2) albumin concentration; ( } 3 \text { ) } \\
\text { bilirubin concentration; (4) histological } \\
\text { stage }\end{array}$ \\
\hline \multirow[t]{2}{*}{ PROGRAMS } & \multirow{2}{*}{$\begin{array}{l}\text { Extremely preterm, } \\
\text { small for gestational } \\
\text { age neonates }\end{array}$} & \multirow[t]{2}{*}{$\mathrm{RCT}$} & \multirow[t]{2}{*}{280} & $\begin{array}{l}\text { Sepsis-free survival up } \\
\text { to day } 14\end{array}$ & Binary & $\begin{array}{l}\text { (1) gestational age at birth; (2) birth } \\
\text { weight }\end{array}$ \\
\hline & & & & Mortality up to day 14 & Binary & $\begin{array}{l}\text { (1) gestational age at birth; (2) birth } \\
\text { weight }\end{array}$ \\
\hline RE01 & $\begin{array}{l}\text { Metastatic renal } \\
\text { carcinoma }\end{array}$ & $\mathrm{RCT}$ & 347 & Time to death & Time-to-event & $\begin{array}{l}\text { (1) WHO score; (2) tumour grade; ( } 3 \text { ) } \\
\text { white cell count }\end{array}$ \\
\hline TIME2 & $\begin{array}{l}\text { Malignant pleural } \\
\text { effusion }\end{array}$ & $\mathrm{RCT}$ & 106 & $\begin{array}{l}\text { Mean breathlessness } \\
\text { over } 42 \text { days }\end{array}$ & Continuous & $\begin{array}{l}\text { (1) breathlessness at baseline; }(2) \\
\text { performance status; ( } 3 \text { ) mesothelioma }\end{array}$ \\
\hline
\end{tabular}

${ }^{a}$ This dataset contained 6,750 patients; however, when assessing this study, we set the sample size to 600 patients to make this more realistic to a trial setting. We chose 600 as this was the median sample size found among trials with a binary primary outcome in a recent review [12]. RCT, randomized controlled trial. 


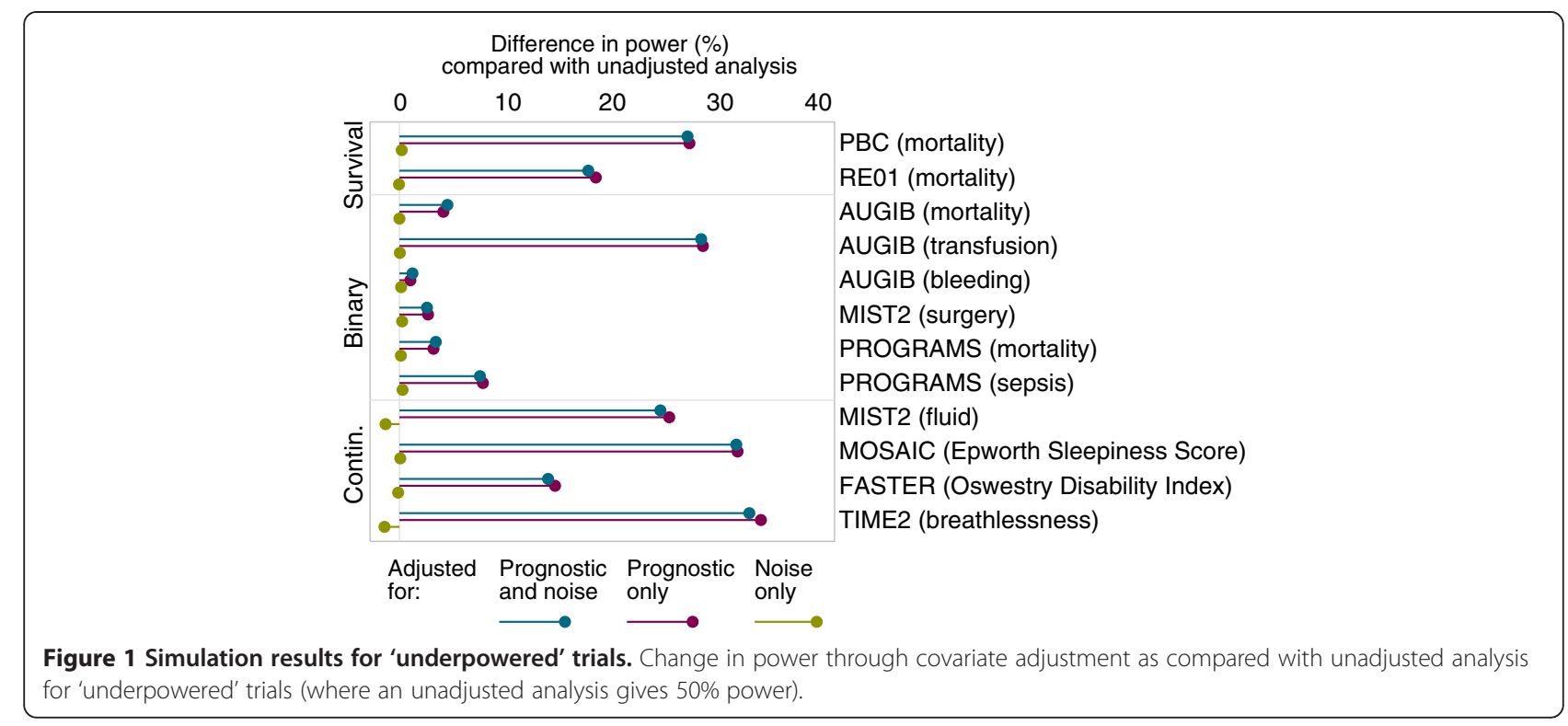

\section{Results}

Results are shown in Figures 1 and 2. Adjustment for prognostic covariates led to substantial increases in power for most outcomes. For 'underpowered' trials, covariate adjustment led to a median increase in power across the 12 outcomes from $50 \%$ to $66.7 \%$ (range 51.0 to $84.4 \%$ ). Power was increased to over $55 \%$ for 8 of 12 outcomes, and to over $75 \%$ for 5 of 12 studies. The increase in power from covariate adjustment was smaller in 'adequately' powered trials, though still substantial. The median increase in power was from $80 \%$ to 92.6\% (range 80.6 to $99.4 \%$ ), and power was increased to over $85 \%$ and $95 \%$ for 8 of 12 and 5 of 12 outcomes, respectively.
Adjustment for 'noise' covariates had little impact on power. For 'underpowered' trials, the largest decrease in power was from $50 \%$ to $48.6 \%$ (range $48.6 \%$ to $50.3 \%$ ), and only 2 of 12 trials had a decrease in power to less than $49 \%$. For 'adequately' powered trials the largest decrease in power was from $80 \%$ to $78.5 \%$ (range $78.5 \%$ to $80.1 \%$ ), and only 1 of 12 trials had a decrease in power to less than $79 \%$.

\section{Discussion}

Although it is well known that adjustment for prognostic covariates can lead to increased power in RCTs, there has been little research attempting to quantify how much of a gain is possible under real trial conditions, or how

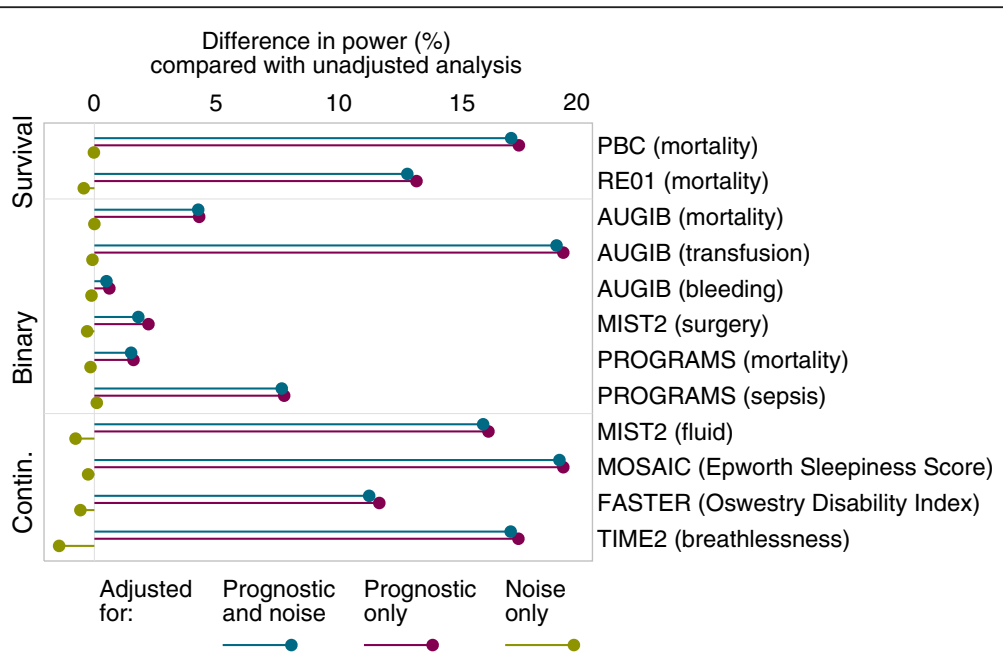

Figure 2 Simulation results for 'adequately powered' trials. Change in power through covariate adjustment as compared with unadjusted analysis for 'adequately powered' trials (where an unadjusted analysis gives $80 \%$ power). 
much of a loss in power can be expected after adjustment for nonprognostic (or 'noise') covariates. A better understanding of this would help researchers to select appropriate covariates to adjust for in their own trials a priori.

In this simulation study using real patient data from a number of differing disease and therapeutic areas, we found that adjustment for strong prognostic covariates led to substantial increases in power in the majority of scenarios we studied. We additionally found that adjustment for 'noise' covariates had little negative impact on power. These two findings suggest that known prognostic covariates should be included in the analysis, in order to increase power. Additionally, a small number of covariates that are suspected (but not known) to be prognostic could also be included in the analysis, since the potential gains in power if they truly are prognostic far outweigh any potential loss in power if they are not prognostic. As discussed elsewhere, the covariates to be adjusted for should be prespecified in the protocol or analysis plan prior to examining the data [42].

The one exception to these recommendations is when there is a small sample size and a binary or time-toevent outcome, as adjustment for covariates in these scenarios could potentially inflate the type I error rate $[11,29]$. This is unlikely to be a problem for trials with a moderate or large sample size. However, it is often difficult to define how small is too small in terms of sample size; if in doubt, methods to account for prognostic covariates with a small sample size have been proposed [29].

Our study has some limitations. First, we only assessed the impact of adjusting for three 'noise' covariates. We chose this number, as we felt that an analysis that adjusts for a small number of covariates is generally viewed more favourably than an analysis adjusting for a large number of covariates [43]. Further research to examine the impact of adjustment for more than three suspected prognostic covariates might be useful. Second, we have not discussed the different methods of accounting for prognostic covariates that can be used. However, these issues have been discussed elsewhere [28,29,44,45], and are beyond the scope of this study. Finally, the AUGIB study was observational, and the participants might have been more heterogeneous than in most randomized trials, which could increase the apparent effect of covariate adjustment. Therefore, results from the AUGIB study should be interpreted cautiously.

\section{Conclusions}

Researchers should adjust for known prognostic covariates. The possible benefits of also adjusting for a small number of suspected prognostic covariates with moderate or large sample sizes far outweigh any risks, and so should also be considered.

\section{Additional file}

Additional file 1: Study information, simulation details and results.

Additional information on each study used, how the simulation study

was performed and simulation results.

\section{Abbreviations}

FASTER: Function After Spinal Treatment, Exercise, and Rehabilitation; MIST2: Second Multi-centre Intra-pleural Sepsis Trial; PBC: primary biliary cirrhosis; RCT: randomized controlled trial; SD: standard deviation;

SE: standard error; tPA: tissue plasminogen activator.

\section{Competing interests}

The authors declare that they have no competing interests.

\section{Authors' contributions}

BCK: conception and design, statistical analysis, interpretation of results and manuscript writing. CJD and TPM: study design, interpretation of results and critical revision of the manuscript. $V J$ : interpretation of results, and critical revision of the manuscript. All authors read and approved the final manuscript.

\section{Acknowledgements}

We thank the reviewers for their helpful suggestions for the manuscript. We also thank the MIST2, TIME2, AUGIB, FASTER, MOSAIC and PROGRAMS teams for the use of their data, without which this article would not have been possible.

No authors received specific funding for this work.

\section{Author details}

${ }^{1}$ Pragmatic Clinical Trials Unit, Queen Mary University of London, London E1 2AB, UK. ${ }^{2}$ Nuffield Department of Medicine, University of Oxford, Oxford OX3 9DU, UK. ${ }^{3}$ Comprehensive Clinical Trials Unit, University College London, London WC1E 6BT, UK. ${ }^{4} \mathrm{MRC}$ Clinical Trials Unit, University College London, London WC2B 6NH, UK.

Received: 15 January 2014 Accepted: 10 April 2014

Published: 23 April 2014

\section{References}

1. Hernandez AV, Eijkemans MJ, Steyerberg EW: Randomized controlled trials with time-to-event outcomes: how much does prespecified covariate adjustment increase power? Ann Epidemiol 2006, 16(1):41-48.

2. Hernandez AV, Steyerberg EW, Butcher I, Mushkudiani N, Taylor GS, Murray GD, Marmarou A, Choi SC, Lu J, Habbema JD, Maas Al: Adjustment for strong predictors of outcome in traumatic brain injury trials: $25 \%$ reduction in sample size requirements in the IMPACT study. J Neurotrauma 2006, 23(9):1295-1303.

3. Hernandez AV, Steyerberg EW, Habbema JD: Covariate adjustment in randomized controlled trials with dichotomous outcomes increases statistical power and reduces sample size requirements. J Clin Epidemiol 2004, 57(5):454-460.

4. Pocock SJ, Assmann SE, Enos LE, Kasten LE: Subgroup analysis, covariate adjustment and baseline comparisons in clinical trial reporting: current practice and problems. Stat Med 2002, 21(19):2917-2930.

5. McHugh GS, Butcher I, Steyerberg EW, Marmarou A, Lu J, Lingsma HF, Weir J, Maas Al, Murray GD: A simulation study evaluating approaches to the analysis of ordinal outcome data in randomized controlled trials in traumatic brain injury: results from the IMPACT project. Clin Trials 2010, 7(1):44-57.

6. Negassa A, Hanley JA: The effect of omitted covariates on confidence interval and study power in binary outcome analysis: a simulation study. Contemp Clin Trials 2007, 28(3):242-248.

7. Senn S: Statistical Issues in Drug Development. Chichester: Wiley; 2007.

8. Turner EL, Perel P, Clayton T, Edwards P, Hernandez AV, Roberts I, Shakur H, Steyerberg EW: CRASH trial collaborators: Covariate adjustment increased power in randomized controlled trials: an example in traumatic brain injury. J Clin Epidemiol 2012, 65(5):474-481.

9. Hauck WW, Anderson S, Marcus SM: Should we adjust for covariates in nonlinear regression analyses of randomized trials? Control Clin Trials 1998, 19(3):249-256. 
10. Robinson LD, Jewell NP: Some surprising results about covariate adjustment in logistic regression models. Int Stat Rev 1991, 58:227-240

11. Kahan BC, Morris TP: Improper analysis of trials randomised using stratified blocks or minimisation. Stat Med 2012, 31(4):328-340.

12. Kahan BC, Morris TP: Reporting and analysis of trials using stratified randomisation in leading medical journals: review and reanalysis. $B M J$ 2012, 345:e5840

13. Kahan BC, Morris TP: Assessing potential sources of clustering in individually randomised trials. BMC Med Res Methodol 2013, 13(1):58.

14. Parzen M, Lipsitz SR, Dear KBG: Does clustering affect the usual test statistics of no treatment effect in a randomized clinical trial? Biom $J$ 1998, 40:385-402.

15. Austin PC, Manca A, Zwarenstein M, Juurlink DN, Stanbrook MB: A substantial and confusing variation exists in handling of baseline covariates in randomized controlled trials: a review of trials published in leading medical journals. J Clin Epidemiol 2010, 63(2):142-153.

16. Hernandez AV, Steyerberg EW, Taylor GS, Marmarou A, Habbema JD, Maas Al: Subgroup analysis and covariate adjustment in randomized clinical trials of traumatic brain injury: a systematic review. Neurosurgery 2005, 57(6):1244-1253. Discussion, 1253

17. Assmann SF, Pocock SJ, Enos LE, Kasten LE: Subgroup analysis and other (mis)uses of baseline data in clinical trials. Lancet 2000, 355(9209):1064-1069.

18. Yu LM, Chan AW, Hopewell S, Deeks JJ, Altman DG: Reporting on covariate adjustment in randomised controlled trials before and after revision of the 2001 CONSORT statement: a literature review. Trials 2010, 11:59.

19. Saquib N, Saquib J, loannidis JP: Practices and impact of primary outcome adjustment in randomized controlled trials: meta-epidemiologic study. BMJ 2013, 347: 44313

20. Schott JM, Bartlett JW, Barnes J, Leung KK, Ourselin S, Fox NC: Reduced sample sizes for atrophy outcomes in Alzheimer's disease trials: baseline adjustment. Neurobiol Aging 2010, 31(8):1452-1462. e2.

21. Rahman NM, Maskell NA, West A, Teoh R, Arnold A, Mackinlay C, Peckham D, Davies CW, Ali N, Kinnear W, Bentley A, Kahan BC, Wrightson JM, Davies HE, Hooper CE, Lee YC, Hedley EL, Crosthwaite N, Choo L, Helm EJ, Gleeson FV, Nunn AJ, Davies RJ: Intrapleural use of tissue plasminogen activator and DNase in pleural infection. N Engl J Med 2011, 365(6):518-526.

22. Pocock SJ, Simon R: Sequential treatment assignment with balancing for prognostic factors in the controlled clinical trial. Biometrics 1975, 31(1):103-115

23. Rosenberger WF, Lachin JM: Randomization in Clinical Trials: Theory and Practice. New York: Wiley; 2002.

24. Scott NW, McPherson GC, Ramsay CR, Campbell MK: The method of minimization for allocation to clinical trials: a review. Control Clin Trials 2002, 23(6):662-674.

25. Taves DR: Minimization: a new method of assigning patients to treatment and control groups. Clin Pharmacol Ther 1974, 15(5):443-453.

26. Van Breukelen GJ: ANCOVA versus change from baseline: more power in randomized studies, more bias in nonrandomized studies [corrected]. J Clin Epidemiol 2006, 59(9):920-925.

27. Egbewale BE, Lewis M, Sim J: Bias, precision and statistical power of analysis of covariance in the analysis of randomized trials with baseline imbalance: a simulation study. BMC Med Res Methodol 2014, 14:49. doi:10.1186/1471-2288-14-49.

28. Kahan BC, Morris TP: Analysis of multicentre trials with continuous outcomes: when and how should we account for centre effects? Stat Med 2013, 32(7):1136-1149.

29. Kahan BC, Morris TP: Adjusting for multiple prognostic factors in the analysis of randomised trials. BMC Med Res Methodol 2013, 13:99.

30. White IR, Thompson SG: Adjusting for partially missing baseline measurements in randomized trials. Stat Med 2005, 24(7):993-1007.

31. Raab GM, Day S, Sales J: How to select covariates to include in the analysis of a clinical trial. Control Clin Trials 2000, 21(4):330-342.

32. Jairath $V$, Kahan BC, Logan RF, Hearnshaw SA, Dore CJ, Travis SP, Murphy MF, Palmer KR: National audit of the use of surgery and radiological embolization after failed endoscopic haemostasis for non-variceal upper gastrointestinal bleeding. Br J Surg 2012, 99(12):1672-1680.

33. Jairath $V$, Kahan BC, Logan RF, Hearnshaw SA, Dore CJ, Travis SP, Murphy MF, Palmer KR: Outcomes following acute nonvariceal upper gastrointestinal bleeding in relation to time to endoscopy: results from a nationwide study. Endoscopy 2012, 44(8):723-730.
34. Jairath V, Kahan BC, Logan RF, Hearnshaw SA, Travis SP, Murphy MF, Palmer KR: Mortality from acute upper gastrointestinal bleeding in the United Kingdom: does it display a 'weekend effect'? Am J Gastroenterol 2011, 106(9):1621-1628.

35. Jairath V, Kahan BC, Stanworth SJ, Logan RF, Hearnshaw SA, Travis SP, Palmer KR, Murphy MF: Prevalence, management, and outcomes of patients with coagulopathy after acute nonvariceal upper gastrointestinal bleeding in the United Kingdom. Transfusion 2013, 53(5):1069-1076.

36. McGregor AH, Dore CJ, Morris TP, Morris S, Jamrozik K: ISSLS prize winner: Function After Spinal Treatment, Exercise, and Rehabilitation (FASTER): a factorial randomized trial to determine whether the functional outcome of spinal surgery can be improved. Spine (Phila Pa 1976) 2011, 36(21):1711-1720.

37. Craig SE, Kohler M, Nicoll D, Bratton DJ, Nunn A, Davies R, Stradling J: Continuous positive airway pressure improves sleepiness but not calculated vascular risk in patients with minimally symptomatic obstructive sleep apnoea: the MOSAIC randomised controlled trial. Thorax 2012, 67(12):1090-1096.

38. Christensen E, Neuberger J, Crowe J, Altman DG, Popper H, Portmann B, Doniach D, Ranek L, Tygstrup N, Williams R: Beneficial effect of azathioprine and prediction of prognosis in primary biliary cirrhosis. Final results of an international trial. Gastroenterology 1985, 89(5):1084-1091.

39. Carr R, Brocklehurst P, Dore CJ, Modi N: Granulocyte-macrophage colony stimulating factor administered as prophylaxis for reduction of sepsis in extremely preterm, small for gestational age neonates (the PROGRAMS trial): a single-blind, multicentre, randomised controlled trial. Lancet 2009, 373(9659):226-233

40. Medical Research Council Renal Cancer Collaborators: Interferon-a and survival in metastatic renal carcinoma: early results of a randomised controlled trial. Lancet 1999, 353(9146):14-17.

41. Davies HE, Mishra EK, Kahan BC, Wrightson JM, Stanton AE, Guhan A Davies CW, Grayez J, Harrison R, Prasad A, Crosthwaite N, Lee YC, Davies RJ, Miller RF, Rahman NM: Effect of an indwelling pleural catheter vs chest tube and talc pleurodesis for relieving dyspnea in patients with malignant pleural effusion: the TIME2 randomized controlled trial. JAMA 2012, 307(22):2383-2389.

42. Chan AW, Tetzlaff JM, Gotzsche PC, Altman DG, Mann H, Berlin JA, Dickersin K, Hróbjartsson A, Schulz KF, Parulekar WR, Krleza-Jeric K, Laupacis A, Moher D: SPIRIT 2013 explanation and elaboration: guidance for protocols of clinical trials. BMJ 2013, 346:e7586.

43. ICH: Harmonised tripartite guideline ICH. Statistical principles for clinical trials. International Conference on Harmonisation E9 Expert Working Group. Stat Med 1999, 18(15):1905-1942.

44. Chu R, Thabane L, Ma J, Holbrook A, Pullenayegum E, Devereaux PJ: Comparing methods to estimate treatment effects on a continuous outcome in multicentre randomized controlled trials: a simulation study. BMC Med Res Methodol 2011, 11:21.

45. Agresti A, Hartzel J: Strategies for comparing treatments on a binary response with multi-centre data. Stat Med 2000, 19(8):1115-1139.

doi:10.1186/1745-6215-15-139

Cite this article as: Kahan et al:: The risks and rewards of covariate adjustment in randomized trials: an assessment of 12 outcomes from 8 studies. Trials 2014 15:139.

\section{Submit your next manuscript to BioMed Central and take full advantage of:}

- Convenient online submission

- Thorough peer review

- No space constraints or color figure charges

- Immediate publication on acceptance

- Inclusion in PubMed, CAS, Scopus and Google Scholar

- Research which is freely available for redistribution 